\title{
Pathology in Undergraduate Training Program
}

Pathology is a study of disease which deals with etiology, pathogenesis and morphological features and the associated clinical features. Pathology acts as a bridge that fills the gap between basic sciences and clinical medicine. With proper understanding of pathological processes, one can understand the disease process. In Nepal, since the beginning of medical school teaching, Pathology as a basic science discipline and is a component of the preclinical medical school curriculum.

Pathology teaching in $19^{\text {th }}$ century was vague, disorganized and very little, though precious. The lectures used to be conducted by surgeons. At Barts, surgeon Sir James Paget had taught surgical pathology. ${ }^{1}$ The real revolution in pathology teaching began in the early 1900 s when, spurred on by increasing understanding of disease mechanisms, pathology began to be accepted as a specialty in its own right. ${ }^{1}$

During the early and mid of $20^{\text {th }}$ century, pathology teaching was a part of clinical teaching with daily, autopsy demonstration. By the late 1980s, significant change had taken place. In many medical schools, debate started regarding relevance of vigorous preclinical teaching. Then system-based approach was incorporated and traditional preclinical course had been abandoned. With this pathology teaching also began to change with pathologists being involved in teaching histology, often alongside pathology to highlight its clinical relevance. In medical schools the pathology teaching time was cut. Autopsy demonstrations, which had been so popular with generations of medical students, were becoming irregular and less well attended.

Though teaching of pathology in blocks to 'avoid fragmentation' has disappeared in western countries; it is still practice in Nepal. In western countries there was traditional practice of teaching general pathology in the first two years and systemic pathology in the clinical years. Now pathology teaching is integrated throughout the course. A consequence of this is that in many medical schools 'pathology' is no longer a recognised subject. In Nepal, pathology is taught in first two years of undergraduate teaching.

Despite all these, Pathology is vital and will remain so, to the proper understanding the disease process. If various clinical subjects are the branches of medicine, pathology is the main stem of it. As Sir William Osler says “As is your Pathology, so is your Medicine.” His words are as true today as they were in his time. Pathology teaching may also include multidisciplinary team meeting as one of the key method of teaching. It not only actively involves Pathologists in teaching learning process, but also an important way of exposing interested students to pathology and, in the author's experience, provides a strong stimulus for eventual choice of pathology as a career. ${ }^{1}$

Dr. Shiva Raj KC, MBBS, MD

Associate Professor, Department of Pathology Kist Medical College Teaching Hospital, Imadole, Lalitpur

\section{Reference:}

1. Domizio P. The changing role of pathology in the undergraduate curriculum. [Internet] . Cited 16th March 2018. Available from: https://www.pathsoc.org/ files/history/c12.pdf 